\title{
Fluid therapy in the emergency department: an expert practice review
}

\author{
Tim Harris, ${ }^{1,2}$ Timothy J Coats, ${ }^{3}$ Mohammed H Elwan ${ }^{3,4}$
}

\begin{abstract}
${ }^{1}$ Academic Department Emergency Medicine, Queen Mary University of London, London, UK

${ }^{2}$ Barts Health NHS Trust, Leicester, UK

${ }^{3}$ Emergency Medicine Academic Group, Department of Cardiovascular Sciences, University of Leicester, Leicester, UK

${ }^{4}$ Department of Emergency Medicine, Alexandria University, Alexandria, Egypt
\end{abstract}

\section{Correspondence to}

Dr Mohammed H Elwan, Emergency Medicine Academic Group, Department of Cardiovascular Sciences, University of Leicester, Leicester LE1 5WW, UK;

mohammed.elwan@alexmed. edu.eg

Received 11 October 2017

Revised 13 April 2018

Accepted 6 May 2018

Published Online First

28 May 2018

Check for updates

To cite: Harris T, Coats TJ, Elwan MH. Emerg Med $J$ 2018:35:511-515.

\section{ABSTRACT}

Intravenous fluid therapy is one of the most common therapeutic interventions performed in the ED and is a long-established treatment. The potential benefits of fluid therapy were initially described by DrW B O'Shaughnessy in 1831 and first administered to an elderly woman with cholera by Dr Thomas Latta in 1832, with a marked initial clinical response. However, it was not until the end of the 19th century that medicine had gained understanding of infection risk that practice became safer and that the practice gained acceptance. The majority of fluid research has been performed on patients with critical illness, most commonly sepsis as this accounts for around two-thirds of shocked patients treated in the ED. However, there are few data to guide clinicians on fluid therapy choices in the non-critically unwell, by far our largest patient group. In this paper, we will discuss the best evidence and controversies for fluid therapy in medically ill patients.

\section{INTRODUCTION}

Intravenous fluid therapy is one of the most common therapeutic interventions performed in the ED, and is a long-established treatment. The potential benefits of fluid therapy were initially described by Dr W B O'Shaughnessy in $1831^{1}$ and first administered to an elderly woman with cholera by Dr Thomas Latta in $1832,{ }^{2}$ with a marked initial clinical response. However, it was not until the end of the 19th century when doctors had gained understanding of infection risk that practice became safer and the intervention gained acceptance.

The majority of research into intravenous fluid therapy has been performed on patients with critical illness, most commonly sepsis as this accounts for around two-thirds of shocked patients treated in the ED. However, there are few data to guide clinicians on fluid therapy choices in the non-critically unwell, by far our largest patient group. In this review, we will discuss the best evidence and controversies for fluid therapy in medically ill patients.

\section{CLINICAL SETTING}

Imagine an elderly patient presenting with a pneumonia, who needs admission to hospital but is not critically unwell (normal observations). What changes in her condition would prompt you to prescribe intravenous fluids? Which fluid would you choose and in what dose? Would you prescribe intravenous fluids if her physiology was normal? This simple daily ED scenario raises a number of questions and there is likely to be great variation in practice. The deceptively simple questions of what fluid should be prescribed and how much are asked of junior doctors on a daily basis.

\section{WHICH FLUID SHOULD I PRESCRIBE?}

Normal saline was described around 150 years ago, initially to store red blood cells. It is hyperosmolar to plasma (osmolality $308 \mathrm{mOsm} / \mathrm{L}$ as compared with $275-285 \mathrm{mOsm} / \mathrm{L}$ ) due to errors in calculating its composition remaining uncorrected since the initial formulation. Solutions balanced both by electrolyte composition and osmolality to approximate to (human) plasma include Hartmann's, Ringer's and Plasma-Lyte (table 1). However, the inability to manufacture plastic that can store bicarbonate sees all solutions replace this with an alternative, most commonly lactate, so the term 'balanced' is relative.

Colloids were developed post-World War II to offer a cheaper alternative to albumin. Manufacturers suggested that, with these fluids, less volume would be needed for a given intravascular effect, thereby reducing tissue oedema and minimising volume infused. Data from the Saline versus Albumin Fluids Evaluation (SAFE) trial, which tested the safety of albumin in $0.9 \%$ saline as compared with $0.9 \%$ saline in patients admitted to intensive care units (ICUs) and requiring fluid bolus administration, suggest that this does not translate to clinical practice with a replacement volume ratio of $1: 1.4$ reported. ${ }^{3}$

Data suggest that emergency physicians (EPs) most commonly prescribe $0.9 \%$ saline while colleagues in critical care favour (so-called) balanced solutions, most commonly Hartmann's Solution in the UK. ${ }^{4}$ Colloids are also more rarely used in the ED.

\section{CRYSTALLOIDS VERSUS COLLOIDS}

The last 20 years has seen advances in our understanding of fluid management, but most of this literature relates to critically ill patients, in particular those who have suffered severe injury or with septic shock. A Cochrane review, which was last updated in 2013, demonstrated an association between the use of colloids (as opposed to crystalloids) and increased mortality. ${ }^{6}$ The 2004 SAFE trial, which took place in Australia where albumin was regularly used in resuscitation in the ICU setting due to low cost, was a large multicentre randomised controlled trial (RCT) that set out to address the issue of the advantages of crystalloid or colloid for resuscitation. ${ }^{3}$ This RCT provided high-quality data to support the safe use of albumin (delivered in 0.9\% saline) as compared with $0.9 \%$ saline in all patient groups other than those with traumatic brain injury (potential harm in brain injury may be related to 
Table 1 Composition of common crystalloid solutions compared with plasma $^{70-72}$

\begin{tabular}{lllllll}
\hline & Plasma & $\begin{array}{l}0.9 \% \\
\text { saline }\end{array}$ & Hartmann's & $\begin{array}{l}\text { Lactated } \\
\text { Ringer's }\end{array}$ & $\begin{array}{l}\text { Ringer's } \\
\text { acetate }\end{array}$ & $\begin{array}{l}\text { Plasma- } \\
\text { Lyte 148 }\end{array}$ \\
\hline $\begin{array}{l}\text { Osmolality } \\
\text { (mOsm/L) }\end{array}$ & $275-295$ & 308 & 278 & 273 & 276 & 294 \\
\hline $\mathrm{pH}$ & $7.35-7.45$ & $4.5-7.0$ & $5.0-7.0$ & $6.0-7.5$ & $6.0-8.0$ & $4.0-8.0$ \\
\hline Sodium (mmol/L) & $135-145$ & 154 & 131 & 130 & 130 & 140 \\
\hline $\begin{array}{l}\text { Potassium } \\
\text { (mmol/L) }\end{array}$ & $3.5-5.0$ & & 5.0 & 4.0 & 5.0 & 5.0 \\
\hline $\begin{array}{l}\text { Magnesium } \\
\text { (mmol/L) }\end{array}$ & $0.8-1.2$ & & & & 1.0 & 1.5 \\
\hline $\begin{array}{l}\text { Chloride (mmol/L) } \\
\text { 9alcium (mmol/L) }\end{array}$ & $2.2-2.6$ & 154 & 111 & 109 & 112 & 98 \\
\hline $\begin{array}{l}\text { Acetate (mmol/L) } \\
\text { Cactate (mmol/L) }\end{array}$ & $1-2$ & 2.0 & 1.4 & 1.0 & 27 \\
\hline $\begin{array}{l}\text { Bicarbonate } \\
\text { (mmol/L) }\end{array}$ & $22-28$ & & 29 & 28 & 27 & \\
\hline $\begin{array}{l}\text { Gluconate } \\
\text { (mmol/L) }\end{array}$ & & & & & & \\
\hline
\end{tabular}

the hypo-osmolar albumin solution contributing to cerebral oedema). The authors followed this with a similarly large RCT to compare $6 \%$ hydroxyethyl starch (delivered in $0.9 \%$ saline) with $0.9 \%$ saline. $^{7}$ This study showed no mortality advantage for either solution but did show a significant increase in the requirement for renal replacement therapy and higher creatinine levels in the patients randomised to 6\% hydroxyethyl starch. Both trials recruited a wide range of patients admitted to ICU requiring fluid resuscitation. The ' $6 \mathrm{~s}$ ' RCT, also performed in the ICU setting but focused on sepsis, reported an increase in mortality for patients resuscitated with $6 \%$ hydroxyethyl starch as compared with Ringer's acetate solution. These and other trials were included in a 2013 Cochrane review, which concluded that the use of starch-based resuscitation fluids was associated with an increased mortality and renal impairment while albumin offered no significant mortality difference to crystalloids. ${ }^{6}$ There were insufficient data to offer conclusions on the use of other colloids. It is likely, but not certain, that this ICU-derived data can be generalised to the ED. This leads us to recommend crystalloids over colloids for initial resuscitation in ED.

\section{WHICH CRYSTALLOID?}

The supraphysiological level of chloride in $0.9 \%$ saline $(154 \mathrm{mmol} / \mathrm{L}$ as compared with around $96-106 \mathrm{mmol} / \mathrm{L}$ in plasma) is associated with a reduced renal blood flow and a higher rate of hyperchloraemic acidosis after large volume infusion. ${ }^{8} 9$ Observational data suggest that the incidence of renal impairment increases with the use of $0.9 \%$ saline as compared with balanced solutions in a wide range of patient groups. ${ }^{10-12}$ A before and after ED study reported an association between chloride rich (saline) compared with chloride poor (eg, lactated Ringer's, Plasma-Lyte) solutions and acute kidney injury. ${ }^{10}$ However, an ICU-based RCT showed no advantage of Plasma-Lyte as compared with saline in mortality or renal function. ${ }^{13}$ A recent ICU RCT showed a lower rate of the composite outcome of death, renal replacement therapy and renal dysfunction in the balanced crystalloid group compared with normal saline. ${ }^{14}$ Another recent ED RCT found no difference in hospital-free days in either saline or balanced crystalloid groups. However, lower incidence of major adverse kidney events was demonstrated in the saline group. ${ }^{15}$

Infusion of $0.9 \%$ saline is the most common cause of in-hospital hyperchloraemic acidosis, while Plasma-Lyte, Ringer's and
Hartmann's solutions are associated with minimal disturbance of blood pH. ${ }^{91216-18}$ The crystalloid-induced changes in lactate, electrolyte, clotting profiles and $\mathrm{pH}$ levels are well described but there are few data to guide clinicians on the impact of these disturbances on final clinical outcomes.

\section{THE BOTTOM LINE}

There is a paucity of ED-based literature so we can only base our practice by extrapolating from ICU studies, and there are no large RCTs that focus on patients who do not require resuscitation. We can guess that a crystalloid will be a reasonable first-choice intravenous fluid and that the type of fluid should be directed by the electrolytes and clinical presentation. Thus, we may choose $0.9 \%$ saline for patients with intracerebral pathology taking advantage of the higher osmolality. However, we may choose a balanced solution for patient with renal impairment and a lower $\mathrm{pH}$ fluid (Plasma-Lyte) for patients with acidosis.

\section{HOW MUCH FLUID SHOULD WE PRESCRIBE?}

This is a more complex and less well-researched question. Fluid therapy is used for resuscitation, to replace losses or prevent dehydration. Fluid research has centred around patients with shock and there is little to guide clinical practice in the other groups. Shock may be defined as life-threatening generalised maldistribution of blood flow resulting in failure to deliver and/ or use adequate amounts of oxygen, leading to tissue hypoxia. The key intervention in hypovolaemic shock and the early phase of septic shock is fluid therapy. Fluids are also used to optimise cardiac output in obstructive and cardiac shock. In all cases, fluids are administered to increase stroke volume and thus cardiac output aiming at correcting tissue hypoperfusion. The underlying physiological principal is that increasing venous return increases stroke volume, the Frank-Starling law of the heart. At rest, the human heart operates below its optimal contraction sarcomere length of $2.2 \mu \mathrm{m}$, increasing towards this with progressive increases in venous return. Beyond this, increasing fluid loading will increase end diastolic pressure but not stroke volume, so risking increased extravascular lung water and tissue oedema. ${ }^{19}$

\section{ASSESSMENT OF VOLUME STATUS}

As assessing stroke volume has (previously) required complex invasive devices, EPs have commonly used surrogate physiological end points to guide fluid resuscitation, such as BP, pulse and urine output. However, as shock may exist with pulse and BP within the normal range, resuscitation targeted at normalising these parameters may still be inadequate. ${ }^{20}$ Oliguria has been criticised as both a trigger and end point for fluid resuscitation and is no longer a therapeutic goal in recent sepsis guidelines. ${ }^{21} 22$

The inadequacy of conventional physiological parameters and observations that patients with higher levels of oxygen delivery had improved survival saw the development of goal-directed therapy (GDT). ${ }^{23-25}$ GDT bases resuscitation on maximising oxygen delivery using predefined haemodynamic goals. This includes indirect parameters such as BP, central venous pressure (CVP) and central venous oxygen saturations and flow-based parameters (stroke volume and cardiac output) in more recent trials. ${ }^{23242627}$ Early studies suggested improved outcomes in a wide range of patients, but three large trials focused on sepsis in the ED setting showed that resuscitation against the goals of CVP and central venous oxygen saturations did not result in improved mortality compared with physician-directed care based on basic physiological parameters. ${ }^{28-32}$ 
Protocolised quantitative resuscitation risks creating fluid delivered in excess of cellular requirements, with some studies suggesting this approach worsens organ perfusion and function as a consequence of fluid overload. ${ }^{33}$ A recent study randomised 212 adults with sepsis in ED in a resource-limited setting to either an early resuscitation protocol guided by clinical and basic monitoring parameters or usual care. Significantly higher mortality was observed in the protocol group. ${ }^{34}$ Similarly, in a large RCT of 3141 patients, significantly higher mortality was observed in sub-Saharan children with severe febrile illness and hypoperfusion randomised to receive a fluid bolus (saline or albumin) versus no bolus. ${ }^{35}$ While both studies were performed in hospitals without intensive care facilities and included respectively a high proportion of HIV-positive patients and children with malaria, these results question the current practice and guidelines of fluid resuscitation, particularly in sepsis.

CVP monitoring has been shown to be unreliable in guiding fluid therapy and is no longer recommended as a resuscitation end point. ${ }^{36-38}$ Although it can be a useful diagnostic parameter in extreme values and when its trend is combined with cardiac output measurement, ${ }^{39}$ it is resource intensive and carries a risk of infection and mechanical complications. Therefore, it is likely a poor choice in ED.

As inferior vena cava (IVC) diameter is a surrogate for CVP, it is subject to the same limitations. Respiratory variation in IVC has been suggested as a non-invasive measure of preload. While the IVC collapsibility index (IVCCI) has initially shown promising results in mechanically ventilated patients, ${ }^{404}$ studies in spontaneously breathing patients suggest a limited role. $^{42}{ }^{43}$ There is considerable interobserver variation ${ }^{44}$ and while an IVCCI $>30 \%-50 \%$ identifies patients likely to improve stroke volume with additional fluid loading, patients with lower levels of collapse $<30 \%-50 \%$ may or may not benefit from additional fluid. ${ }^{42}$

Lactate is commonly used in the ED as a marker of hypoperfusion. High lactate is an independent predictor of mortality in critically ill patients. ${ }^{45}{ }^{46}$ Its use has been recommended by local and international guidelines to risk stratify patients with suspected sepsis and guide treatment. ${ }^{5025}$ While failure to clear lactate is an ominous sign, good lactate clearance may be a misleading resuscitation end point. ${ }^{47}$ This is because lactataemia is both a product of aerobic mechanisms and driven by physiological/pathophysiological increases in sympathetic drive (stress response) and drug effects (eg, epinephrine, salbutamol). ${ }^{48}$ Thus, lactate may clear as the driving stimulus is treated (pain, agitation, medication) or as a consequence of adequate resuscitation. Lactataemia with accompanying acidosis is associated with a worse prognosis as compared with lactataemia alone. ${ }^{49} 50$

\section{THE FLUID CHALLENGE}

The ability to increase stroke volume and cardiac output in response to preload challenge is termed preload responsiveness and is most commonly defined as an increase of $>10 \%-15 \%$ following a fluid challenge. A fluid challenge is different from fluid loading, where fluids are administered without real-time monitoring. ${ }^{51}$ Fluid challenge, on the other hand, is a test for preload responsiveness and can be used as a controlled method for resuscitation, where a repeated fluid challenge is guided by the haemodynamic response.

The optimal volume and rate of infusion of a fluid challenge is unknown. A volume of $500 \mathrm{~mL}$ is the most commonly usedlarger volumes may risk overload and smaller volumes may not represent a challenge. Evidence suggests that infusion over less than $30 \mathrm{~min}$ is more effective in detecting fluid responders. ${ }^{5253}$

The main disadvantage of fluid challenge is that a negative test (with no increase in cardiac output or stroke volume) would mean that fluids have been irreversibly administered to patient. This is particularly important in patients at risk of overload (eg, cardiac failure and renal impairment) and if repeated fluid challenges are to be given in a short time frame. In this context, passive leg raise (PLR), a reversible self-fluid challenge, may be a more suitable alternative. PLR predicts fluid responsiveness in both spontaneously breathing and mechanically ventilated patients. ${ }^{54-56}$ Stroke volume changes resulting from a PLR may occur from some seconds to minutes after the manoeuvre and are transitory, so best assessed with continuous cardiac output monitoring or by a skilled echocardiography operator. ${ }^{5457}$

\section{SHOULD WE ASSESS FLUID RESPONSIVENESS?}

Fluid responsiveness is dictated by tissue oxygen requirements and cardiac performance, not intravascular volume. Thus, patients may be hypervolaemic and fluid responsive (eg, patients with sepsis post initial fluid resuscitation) or hypovolaemic but not fluid responsive (eg, dehydration in the setting of sepsis with acute, severely impaired left ventricular function). There is a sound theoretical framework to base fluid resuscitation on identifying fluid responders. Under resuscitation risks inadequate oxygen delivery for optimal tissue perfusion while prescribing fluids to non-responders risks fluid overload. ${ }^{58}$ Fluid overload in the ICU population is associated with increased mortality, length of stay, time undergoing mechanical ventilation and renal impairment. ${ }^{59-64}$ Current use of physiological markers such as pulse and BP without measurement of cardiac function means that EPs will be unaware of the effect of fluid therapy on stroke volume/cardiac output and how this is altered by either unknown existing or acquired cardiac dysfunction, or improved cardiac function resulting from medical therapy. Assessing fluid responsiveness is associated with an altered volume of fluids administered in both the ED and ICU. ${ }^{65-67}$ However, a recent systematic review found no mortality benefit for assessing fluid responsiveness in the ED setting. ${ }^{68}$ This included only eight studies and 489 patients highlighting the paucity of research in this field. Trials to date have focused on identifying fluid responders to maximise cardiac output and stroke volume to maximise oxygen delivery with the assumption that shock-related organ dysfunction will be rapidly reversed. However, the benefit may be that of reducing the harm of unnecessary fluid resuscitation and preventing the harm of fluid overload by identifying fluid non-responders for whom an alternative resuscitation strategy is preferred. Indeed, recent studies on the ED population report the proportion of fluid responders as $31 \%-85 \%$, similar to on arrival on ICU at a later stage of resuscitation. ${ }^{6768} \mathrm{~A}$ meta-analysis of fluid bolus therapy in the ICU setting identified an increase in cardiac index of $800 \mathrm{~mL} / \mathrm{min} / \mathrm{m}^{2}$ immediately following the fluid bolus but this fell to $300 \mathrm{~mL} / \mathrm{min} / \mathrm{m}^{2}$ after $60 \mathrm{~min}$. The figures for mean arterial pressure and pulse rate were $7-3 \mathrm{~mm} \mathrm{Hg}$ and $2-1$ beats per minute. ${ }^{69}$ Observational data on 500 diverse ED patients who received a fluid bolus also suggest that fluid therapy has a similarly limited effect on improving BP and pulse in the ED setting. ${ }^{53}$ This study reported an increase in BP and decrease in HR 10 min after administering a fluid bolus but these had returned to baseline by 1 hour, presumably as the fluid delivered had redistributed from the intravascular space. There was a significant increase in RR and decrease in temperature following fluid therapy. 
A simple preload/cardiac output relationship (the Frank Starling law of the heart) does not describe real life changes which are also influenced by contractility, HR, vascular tone, genetics and pre-existing disease. For example, in exercise cardiac output can increase fivefold with minimal change in preload. ${ }^{19}$ In Guytonian physiology, cardiac output is driven by local tissue requirements, for example, to supply oxygen to skeletal muscles in response to increased demand. The response of most normal humans who give themselves a fluid load is to increase bladder volume and not stroke volume.

\section{THE BOTTOM LINE}

It is important to appreciate the limits of what intravenous fluids can do. In sepsis there may be an intravascular fluid deficit; however, this is only one element in a complex abnormality of cardiac and both macrovascular and microvascular function. Fluid infusion may help some patients, but in patients without tissue hypoxia the lack of increased tissue demand may see fluid therapy simply redistributed and excreted. In sepsis, fluid loading may increase capillary leak to extravascular tissues and is likely to be harmful, so other interventions (eg, pressor therapy) may be required to improve tissue perfusion.

To return to the case scenarios presented, for resuscitation we support the use of crystalloids over colloids, with the choice of fluid based on electrolyte disturbance and pathology being treated. A balanced solution would be the fluid of choice unless there were specific reasons to choose $0.9 \%$ saline, such as concerns around cerebral oedema or elevated intracranial pressure. Suitable triggers for resuscitation fluid are organ failure and/or evidence (clinical or biochemical) of hypoperfusion. The risks of high-volume resuscitation are increasingly evident but the question of how much fluid is yet to be adequately answered. A pragmatic approach in the initial period is to repeat $500 \mathrm{~mL}$ boluses where there is no evidence of harm (such as evidence pulmonary oedema) and there is evidence of clinical or biochemical benefit (increasing BP, reducing pulse, decreasing lactate, improving metabolic acidosis). Focused echo may be useful in the initial assessment to identify shock aetiology and guide therapy, especially where poor ventricular function is identified. In the absence of any requirements for resuscitation fluids, oral fluids may be the safest option, where these are available and the patient can tolerate them.

Large, ED-based clinical trials are required to clarify whether a resuscitation strategy based around fluid responsiveness improves outcomes as compared with usual care, whether fluid therapy is better titrated to tissue perfusion as opposed to cardiovascular end points and whether oral fluids may be used in place of intravenous in patients with no evidence of tissue hypoperfusion.

\section{CONCLUSIONS}

Crystalloids are the first choice for non-blood product fluid resuscitation, balanced solutions may offer a small advantage in preserving renal function as compared with $0.9 \%$ saline. Under-resuscitation and over-resuscitation are associated with harm in critically unwell patients. Stroke volume assessment to a fluid challenge is widely used to guide fluid volumes in critical care, but is not well studied in the ED population and the optimal time of delivery and infused volumes are not established. A significant proportion of patients in the ED do not respond to infused fluids, thus applying simple physiological 'rules' to this complex situation may lead to overinfusion and harm. We should be wary of applying evidence derived from ICU patients, as the majority of ED patients are not critically ill and so should lobby the funders of research to invest in the large clinical trials that are required to better define optimal fluid therapy in emergency care.

Correction notice This article has been corrected since it was published Online Firts. Two dates in the abstract have been corrected (1831 and 1832).

Funding The authors have not declared a specific grant for this research from any funding agency in the public, commercial or not-for-profit sectors.

Competing interests None declared.

Patient consent Not required.

Provenance and peer review Not commissioned; externally peer reviewed.

(C) Article author(s) (or their employer(s) unless otherwise stated in the text of the article) 2018. All rights reserved. No commercial use is permitted unless otherwise expressly granted.

\section{REFERENCES}

1 O'Shaughnessy W. Proposal of a new method of treating the blue epidemic cholera by the injection of highly-oxygenised salts into the venous system: Read before the Westminster Medical Society, Saturday, Dec. 3rd. The Lancet 1831;17:366-71.

2 Latta T, cholera M. Documents communicated by the Central Board of Health, London, relative to the treatment of cholera by the copious injection of aqueous and saline fluids into the veins. Lancet 1832;2:12.

3 Finfer S, Bellomo R, Boyce N, et al. A comparison of albumin and saline for fluid resuscitation in the intensive care unit. N Engl J Med 2004;350:2247-56.

4 McIntyre L, Rowe BH, Walsh TS, et al. Multicountry survey of emergency and critical care medicine physicians' fluid resuscitation practices for adult patients with early septic shock. BMJ Open 2016;6:e010041.

5 Jiwaji Z, Brady S, McIntyre LA, et al. Emergency department management of early sepsis: a national survey of emergency medicine and intensive care consultants. Emerg Med J 2014;31:1000-5

6 Perel P, Roberts I, Ker K. Colloids versus crystalloids for fluid resuscitation in critically ill patients. Cochrane Database Syst Rev 2013;13.

7 Myburgh JA, Finfer S, Bellomo R, et al. Hydroxyethyl starch or saline for fluid resuscitation in intensive care. N Engl J Med 2012;367:1901-11.

8 Wilcox CS. Regulation of renal blood flow by plasma chloride. J Clin Invest 1983;71:726-35.

9 Yunos NM, Bellomo R, Story D, et al. Bench-to-bedside review: chloride in critical illness. Crit Care 2010;14:226-36.

10 Yunos NM, Bellomo R, Taylor DM, et al. Renal effects of an emergency department chloride-restrictive intravenous fluid strategy in patients admitted to hospital for more than 48 hours. Emerg Med Australas 2017;29:643-9.

11 Yunos NM, Bellomo R, Hegarty C, et al. Association between a chloride-liberal vs chloride-restrictive intravenous fluid administration strategy and kidney injury in critically ill adults. JAMA 2012;308:1566-72.

12 Young JB, Utter GH, Schermer CR, et al. Saline versus Plasma-Lyte A in initial resuscitation of trauma patients: a randomized trial. Ann Surg 2014;259:255-62.

13 Young P, Bailey M, Beasley R, et al. Effect of a buffered crystalloid solution vs saline on acute kidney injury among patients in the intensive care unit: the SPLIT randomized clinical trial. JAMA 2015;314:1701-10.

14 Semler MW, Self WH, Wanderer JP, et al. Balanced crystalloids versus saline in critically ill adults. N Engl J Med 2018;378:829-39.

15 Self WH, Semler MW, Wanderer JP, et al. Balanced crystalloids versus saline in noncritically ill adults. N Eng/ J Med 2018;378:819-28.

16 Williams EL, Hildebrand KL, McCormick SA, et al. The effect of intravenous lactated Ringer's solution versus $0.9 \%$ sodium chloride solution on serum osmolality in human volunteers. Anesth Analg 1999;88:999-1003.

17 Shaw AD, Bagshaw SM, Goldstein SL, et al. Major complications, mortality, and resource utilization after open abdominal surgery: $0.9 \%$ saline compared to PlasmaLyte. Ann Surg 2012;255:821-9.

18 Khajavi MR, Etezadi F, Moharari RS, et al. Effects of normal saline vs. lactated ringer's during renal transplantation. Ren Fail 2008;30:535-9.

19 Magder S. Volume and its relationship to cardiac output and venous return. Crit Care 2016;20:271.

20 Wo CC, Shoemaker WC, Appel PL, et al. Unreliability of blood pressure and heart rate to evaluate cardiac output in emergency resuscitation and critical illness. Crit Care Med 1993;21:218-23.

21 Schortgen F, Schetz M. Does this critically ill patient with oliguria need more fluids, a vasopressor, or neither? Springer, 2017.

22 Rhodes A, Evans LE, Alhazzani W, et al. Surviving sepsis campaign: International Guidelines for Management of Sepsis and Septic Shock: 2016. Crit Care Med 2017;45:486-552. 
23 Durham RM, Neunaber K, Mazuski JE, et al. The use of oxygen consumption and delivery as endpoints for resuscitation in critically ill patients. J Trauma 1996:41:32-40.

24 Bishop MH, Shoemaker WC, Appel PL, et al. Prospective, randomized trial of survivor values of cardiac index, oxygen delivery, and oxygen consumption as resuscitation endpoints in severe trauma. J Trauma 1995;38:780-7.

25 Crowl AC, Young JS, Kahler DM, et al. Occult hypoperfusion is associated with increased morbidity in patients undergoing early femur fracture fixation. J Trauma 2000;48:260-7.

26 Rady MY, Rivers EP, Nowak RM. Resuscitation of the critically ill in the ED: responses of blood pressure, heart rate, shock index, central venous oxygen saturation, and lactate. Am J Emerg Med 1996;14:218-25.

27 Pearse RM, Harrison DA, MacDonald N, et al. Effect of a perioperative, cardiac outputguided hemodynamic therapy algorithm on outcomes following major gastrointestinal surgery: a randomized clinical trial and systematic review. JAMA 2014;311:2181-90.

28 Angus DC, Barnato AE, Bell D, et al. A systematic review and meta-analysis of early goal-directed therapy for septic shock: the ARISE, ProCESS and ProMISe Investigators. Intensive Care Med 2015;41:1549-60.

29 Mouncey PR, Osborn TM, Power GS, et al. Trial of early, goal-directed resuscitation for septic shock. N Engl J Med 2015;372:1301-11.

30 Yealy DM, Kellum JA, Huang DT, et al. A randomized trial of protocol-based care for early septic shock. N Engl J Med 2014;370:1683-93.

31 Peake SL, Delaney A, Bailey M, et al. Goal-directed resuscitation for patients with early septic shock. N Engl J Med 2014;371:1496-506.

32 Rivers ENB, Havstad S, Ressler J, et al. Early goal-directed therapy in the treatment of severe sepsis and septic shock. New England Journal of Medicine. New England Journal of Medicine 2001;8:1368-77.

33 Hjortrup PB, Haase N, Bundgaard $\mathrm{H}$, et al. Restricting volumes of resuscitation fluid in adults with septic shock after initial management: the CLASSIC randomised, parallelgroup, multicentre feasibility trial. Intensive Care Med 2016;42:1695-705.

34 Andrews B, Semler MW, Muchemwa L, et al. Effect of an early resuscitation protocol on in-hospital mortality among adults with sepsis and hypotension. JAMA 2017:318:1233.

35 Maitland K, Kiguli S, Opoka RO, et al. Mortality after fluid bolus in African children with severe infection. N Engl J Med 2011;364:2483-95.

36 Marik PE, Baram M, Vahid B. Does central venous pressure predict fluid responsiveness? A systematic review of the literature and the tale of seven mares. Chest 2008;134:172-8

37 Marik PE, Cavallazzi R. Does the central venous pressure predict fluid responsiveness? An updated meta-analysis and a plea for some common sense. Crit Care Med 2013:41:1774-81.

38 Cecconi M, De Backer D, Antonelli M, et al. Consensus on circulatory shock and hemodynamic monitoring. Task force of the European Society of Intensive Care Medicine. Intensive Care Med 2014;40:1795-815.

39 Magder S. Understanding central venous pressure: not a preload index? Curr Opin Crit Care 2015:21:369-75

40 Feissel M, Michard F, Faller JP, et al. The respiratory variation in inferior vena cava diameter as a guide to fluid therapy. Intensive Care Med 2004;30:1834-7.

41 Barbier C, Loubières Y, Schmit C, et al. Respiratory changes in inferior vena cava diameter are helpful in predicting fluid responsiveness in ventilated septic patients. Intensive Care Med 2004;30:1740-6.

42 Long $\mathrm{E}$, Oakley $\mathrm{E}$, Duke T, et al. Does respiratory variation in inferior vena cava diameter predict fluid responsiveness: a systematic review and meta-analysis. Shock 2017:47:550-9.

43 Lee CW, Kory PD, Arntfield RT. Development of a fluid resuscitation protocol using inferior vena cava and lung ultrasound. J Crit Care 2016;31:96-100.

44 Bowra J, Uwagboe V, Goudie A, et al. Interrater agreement between expert and novice in measuring inferior vena cava diameter and collapsibility index. Emerg Med Australas 2015:27:295-9.

45 Howell MD, Donnino M, Clardy P, et al. Occult hypoperfusion and mortality in patients with suspected infection. Intensive Care Med 2007;33:1892-9.

46 Kjelland CB, Djogovic D. The role of serum lactate in the acute care setting. J Intensive Care Med 2010;25:286-300.

47 Marik PE, Bellomo R, Demla V. Lactate clearance as a target of therapy in sepsis: a flawed paradigm. OA Critical Care 2013;1:3.
48 Bakker J, Nijsten MW, Jansen TC. Clinical use of lactate monitoring in critically ill patients. Ann Intensive Care 2013;3:12

49 Lee SW, Hong YS, Park DW, et al. Lactic acidosis not hyperlactatemia as a predictor of in hospital mortality in septic emergency patients. Emerg Med J 2008:25:659-65.

50 Fuller BM, Dellinger RP. Lactate as a hemodynamic marker in the critically ill. Curr Opin Crit Care 2012:18:267-72.

51 Cecconi M, Singer B, Rhodes A. The fluid challenge: annual update in intensive care and emergency medicine 2011: Springer, 2011:332-9.

52 Toscani L, Aya HD, Antonakaki D, et al. What is the impact of the fluid challenge technique on diagnosis of fluid responsiveness? A systematic review and metaanalysis. Crit Care 2017;21:207.

53 Bihari S, Teubner DJ, Prakash S, et al. Fluid bolus therapy in emergency department patients: Indications and physiological changes. Emerg Med Australas 2016;28:531-7.

54 Monnet X, Marik P, Teboul JL. Passive leg raising for predicting fluid responsiveness: a systematic review and meta-analysis. Intensive Care Med 2016;42:1935-47.

55 Cherpanath TG, Hirsch A, Geerts BF, et al. Predicting fluid responsiveness by passive leg raising: a systematic review and meta-analysis of 23 clinical trials. Crit Care Med 2016;44:981-91.

56 Préau S, Saulnier F, Dewavrin F, et al. Passive leg raising is predictive of fluid responsiveness in spontaneously breathing patients with severe sepsis or acute pancreatitis. Crit Care Med 2010;38:819-25.

57 Monnet X, Teboul JL. Passive leg raising: five rules, not a drop of fluid. Crit Care 2015;19:18.

58 Chang DW, Huynh R, Sandoval E, et al. Volume of fluids administered during resuscitation for severe sepsis and septic shock and the development of the acute respiratory distress syndrome. J Crit Care 2014;29:1011-5.

59 Acheampong A, Vincent JL. A positive fluid balance is an independent prognostic factor in patients with sepsis. Crit Care 2015;19:251.

60 Sadaka F, Juarez M, Naydenov S, et al. Fluid resuscitation in septic shock: the effect of increasing fluid balance on mortality. J Intensive Care Med 2014:29:213-7.

61 Arikan AA, Zappitelli M, Goldstein SL, et al. Fluid overload is associated with impaired oxygenation and morbidity in critically ill children. Pediatr Crit Care Med 2012;13:253-8.

62 Wang N, Jiang L, Zhu B, et al. Fluid balance and mortality in critically ill patients with acute kidney injury: a multicenter prospective epidemiological study. Crit Care 2015;19:371.

63 Boyd JH, Forbes J, Nakada TA, et al. Fluid resuscitation in septic shock: a positive fluid balance and elevated central venous pressure are associated with increased mortality. Crit Care Med 2011;39:259-65.

64 Silversides JA, Major E, Ferguson AJ, et al. Conservative fluid management or deresuscitation for patients with sepsis or acute respiratory distress syndrome following the resuscitation phase of critical illness: a systematic review and metaanalysis. Intensive Care Med 2017:43:155-70.

65 Richard JC, Bayle F, Bourdin G, et al. Preload dependence indices to titrate volume expansion during septic shock: a randomized controlled trial. Crit Care 2015;19:5.

66 Bednarczyk JM, Fridfinnson JA, Kumar A, et al. Incorporating ddynamic assessment of fluid responsiveness into goal-directed therapy. Crit Care Med 2017:45:1538-45.

67 Hou PC, Filbin MR, Napoli A, et al. Cardiac Output Monitoring Managing Intravenous Therapy (COMMIT) to treat emergency department patients with sepsis. Shock 2016:46:132-8

68 Elwan MH, Roshdy A, Elsharkawy EM, et al. The haemodynamic dilemma in emergency care: is fluid responsiveness the answer? A systematic review. Scand J Trauma Resusc Emerg Med 2017;25:25.

69 Glassford NJ, Eastwood GM, Bellomo R. Physiological changes after fluid bolus therapy in sepsis: a systematic review of contemporary data. Crit Care 2014;18:181.

70 Reddy S, Weinberg L, Young P. Crystalloid fluid therapy. Crit Care 2016;20:59.

71 Padhi S, Bullock I, Li L, et al. Intravenous fluid therapy for adults in hospital: summary of NICE guidance. BMJ 2013;347:f7073.

72 National Institute for Clinical Excellence. Intravenous fluid therapy in adults in hospital-NICE clinical guideline. 2013.

73 National Institute for Health and Care Excellence. Sepsis: recognition, diagnosis and early management. 2016. 